\title{
Comparatismo cimarrón: un método supranacional
}

\author{
Marcela Croce ${ }^{\bullet}$
}

Universidad de Buenos Aires

\section{Resumen}

El artículo establece la necesidad de desarrollar una teoría y un método enunciados desde Latinoamérica para abordar la cultura latinoamericana, libre de los modelos de academias metropolitanas que postulan abolir el colonialismo pero operan una colonización intelectual sobre el mismo objeto abordado. La propuesta consiste en una variante del comparatismo que articula la dimensión comarcana postulada por Ángel Rama, la cual permite organizar segmentos dentro de la cultura continental, y la dimensión supranacional que se ofrece como síntesis respecto de los abordajes transnacionales. Además de trazar los principios de este comparatismo que se aparta de la formulación clásica del método e incorpora teorías propiamente latinoamericanas, el texto presenta a Brasil como ejemplo puntual de abordaje comparatista respecto de Hispanoamérica.

\section{Palabras clave}

· Teoría latinoamericana $\cdot$ Comparatismo $\cdot$ Comarcas 


\section{Abstract}

The article establishes the need to develop a theory and a method proposed from a Latin America stance to approach the Latin American culture, free of the models of metropolitan academies that postulate the abolition of colonialism but signify an intellectual colonization on the same object addressed. The proposal consists of a variant of comparatism that articulates the "comarcana» (regional) dimension postulated by Ángel Rama, which allows to organize segments of the continental culture and the supranational dimension both offered as a synthesis regarding transnational approaches. In addition to tracing the principles of this comparatism that deviates from the classical formulation of the method and incorporates properly Latin American theories, the text presents Brazil as a accurate example of a comparative approach to Latin America.

\section{Key words}

· Latin American Theory · Comparatism · Comarcas

En 1848, Marx azuzó un espantajo ante la soberbia de la burguesía que no alcanzaba a ver las consecuencias funestas de sus propias políticas. «Un fantasma recorre Europa» fue menos una advertencia a quienes no querían escuchar ( $\mathrm{y}$ a quienes Marx tampoco deseaba hablarles) que una retórica eficaz —asistida por brujas shakespereanas y por la recaída gótica del romanticismo - para lanzar la consigna libre de metáforas y auspiciosamente ecuménica: «Proletarios del mundo, uníos». Sin pretender una emulación marxista, aunque adscribiéndome a ese despliegue discursivo con idéntico propósito de descalabro de un sistema que se deshilacha, proclamo una necesidad que muchos han visto pero actualmente se resisten a defender con lo que conlleva, del mismo modo en que multitud de revolucionarios se mostraron horrorizados frente a las prácticas brutales que iban asociadas al cambio radical. La necesidad es la de una teoría independiente para abordar la cultura latinoamericana. Las vacilaciones conciernen a la fascinación que incluso críticos altamente preparados para acometer la tarea exhiben por las teorías metropolitanas que abusan de las variantes del colonialismo - poscolonialismo, decolonialismo, subalternidad - para no desprenderse en verdad de su estela insidiosa. 
Admito que simplifico por cuestiones de énfasis: la seducción que afecta a los críticos latinoamericanos suele radicar en la academia central (norteamericana y, solo en segunda instancia ahora, europea) sin exclusividad de los colonialismos teóricos, pero sí de los prácticos. Pensar con categorías ajenas se ha vuelto una costumbre y devino ritual de cita de autoridad en textos, clases y conferencias. Por supuesto, no se trata de arremeter contra todo lo que no demuestre una prosapia latinoamericana estricta —un absurdo en sí mismo, por la composición mestiza de América Latina - o contra lo que carezca de credenciales localistas administradas según un ufanismo ridículo. Se trata de señalar, apenas, que esas categorías que parecen tan propicias para los latinoamericanos responden a una colonización extensiva que de ningún modo puede quedar mitigada por la circunstancia de que sea autoinfligida. Ni los vehementes pontificadores de las cátedras prestigiosas, ni los subalternos que ocupan un lugar de privilegio en las universidades metropolitanas ni los latinoamericanos que disputan espacios académicos centrales pueden insubordinarse ante esos principios si quieren conservar los lugares conseguidos en el sistema. Un locus de enunciación tan rigurosamente establecido se apresura a descartar lo que proviene de esa misma periferia a la cual dicen dedicarse. Del otro lado, por supuesto, rezar a Jesucristo y hablar en espańol tampoco son condiciones suficientes para intentos superadores.

Sin embargo, entregarme a defenestrar modelos o a condenar prácticas sería, además de inquisitorial, improductivo. Me abstengo por lo mismo de profusas y engorrosas citas y de catálogos de nombres como los que se estila desplegar para indicar que se agotó la bibliografía sobre un tema, o al menos que se conoce lo más actual al respecto. Semejante privación responde a una voluntad heurística. Como en el ejemplo de Marx procuro, antes que abundar, dialectizar, no desde la reiteración mecánica del modelo de tesis-antítesis-síntesis sino a partir de la advertencia de Gutiérrez Girardot de que, en lengua española, ese circuito anuló o salteó «los dos momentos esenciales de la dialéctica: la intermediación y la absorción, esto es, las transiciones» (1985: 130). El Manifiesto Comunista evidenciaba su pasión por los logros de la burguesía, que había logrado en el tiempo de su dominio más avances en el saber que cualquier otra clase en cualquier etapa de la historia; el problema era que había perdido su vocación combativa y había mutado a clase explotadora. Con la modestia a que me somete la diferencia en la dimensión de la tarea, no pretendo demoler las teorías metropolitanas que abrieron el camino hasta aquí sino apartarme de ellas en el punto en que se han convertido antes en un impedimento que en una herramienta para ampliar el campo del saber. $\mathrm{O}$ tal vez, obnubiladas por su afán universalista, han perdido de vista el modo en que un mestizaje abusivo reclama una especificidad de la mezcla, que ni siquiera es común a toda América Latina. En este punto cabe insistir en que la verdadera «utopía de América», como la llamaba Pedro Henríquez Ureña, es la posibilidad de unificar bajo ese sustantivo tanta diversidad.

Precisamente en el ensayo que tituló La utopía de América (conferencia dictada en la Universidad de La Plata, en el marco del reformismo surgido en 1918), Henríquez Ureńa imaginó una sociedad completamente alfabetizada en la cual el pueblo actuaba como un intelectual marcando criterios. A ese pueblo americano - usaba el adjetivo prescindiendo deliberadamente de Estados Unidos, escamoteando en ese solo gesto la apropiación desenfadada de quienes se arrogan la exclusividad de América - atribuía una acción creadora: «Mira al pasado, y crea la historia; mira 
al futuro, y crea las utopías» (2000: 270). Me atrevo a agregar el momento que omitió y que me permite justificarme en la tarea que presento: mira al presente y crea la teoría. Es ese el ímpetu que hoy convoca a la intelectualidad continental que participa de la que Ana Pizarro llamó «estirpe de sońadores rigurosos» (1985: 10).

Lo que quisiera proponer aquí es una teoría cultural para el territorio periférico que es América Latina. Desde ya, no es una novedad sino un afán de sistematización lo que la sostiene. Por eso procuro reactualizar los planteos que en los años 60 ocuparon a Ángel Rama en los estudios literarios, a Darcy Ribeiro en la antropología, a un conjunto de sociólogos y economistas reunidos en torno a la Teoría de la Dependencia (de los que resaltan los nombres de Fernando Henrique Cardoso y Theotônio dos Santos), a Arturo Andrés Roig en la filosofía (acompañado por los creadores y los practicantes de la Filosofía de la Liberación) y a multitud de artistas, periodistas, escritores que sostuvieron emprendimientos similares de afirmación latinoamericana. Y si tomo los 60 como momento clave en que eclosionan las iniciativas — con el impulso que significó la Revolución Cubana- es apenas para poner un límite a una idea que arraiga ya en Bolívar y que se arrastra a lo largo de dos siglos con la amargura de continuar como proyecto inconcluso.

El dependentismo había sido tan preciso como desolador en sus diagnósticos; acaso por esa desazón que instalaba la comprobación económica, los estudiosos de la cultura procuraron recomponer no ya un optimismo imposible sino una esperanza. Su función era tanto constructiva como reconstructiva pero, sobre todo, se proponía desbaratar la proporcionalidad pretendidamente directa entre dependencia económica y cultural. En la misma época, los procesos de descolonización en África (especialmente en el Magreb), encabezados por el martiniqueño Frantz Fanon, que superaba las limitaciones de la négritude lanzada por otro martiniqueño, Aimé Césaire, producían una teoría que lograba expandirse hacia América Latina. Me detengo en Fanon no ya por su condición de miembro de la intelectualidad colonial de la cual se desgarró para ponerse del lado de los oprimidos, sino porque, en vez de apelar a las consignas marxistas que empleé al iniciar este trabajo, recuperó el anonimato de La Internacional para dar título a su obra más perdurable: Los condenados de la tierra. Y también apunto a Fanon porque encontró la discursividad que estimo adecuada para la propuesta que intento formular: esa forma tan libre y flexible del ensayo, que alterna las convicciones indeclinables con la enunciación sinuosa de quien sabe que está convirtiendo una opinión personal en una ética del pronunciamiento.

Una tercera razón para apelar a Fanon es la dificultad que América Latina, tan orgullosamente hispánica algunas veces, tan apasionadamente indigenista otras veces, ha exhibido al mitigar no solamente el componente negro - agredido y segregado, él mismo ingresado a América por el tráfico esclavista que la codicia conquistadora instaló- sino también el sector francófono que se ubica en el Caribe. No se trata exclusivamente de revisar el estatuto que les corresponde a los territorios de ultramar en su inserción latinoamericana (y El discurso antillano de Édouard Glissant es una magnífica indagación al respecto), sino también de explicar por qué Haití, primera república latinoamericana, sigue siendo un convidado de piedra en los estudios continentales, excepto en los «momentos felices» que identificaba Henríquez Ureña (quien siempre reserva términos despectivos para los haitianos y no trepida en manifestar su convicción de que la República Dominicana hubiera sido un país próspero de no haber tenido que compartir la isla con los oscuros 
vecinos soliviantados ante el dominio francés) de los cuales la Revolución Cubana y la participación en ella de René Depestre acaso sea el ejemplo ideal.

Para pensar esa integración del Caribe francés con el resto del Caribe pero no con toda América Latina, Ángel Rama ideó un instrumento conceptual que me permite comenzar a perfilar mi tentativa: el de las comarcas. Se trata de una herramienta metodológica a la vez que de una advertencia teórica para sostener la «utopía de América». Concebir al continente como sumatoria de comarcas permite eludir los límites territoriales (más específicamente, los límites que traza el Estado-nación en cada caso), pero su probidad epistémica se clausura allí si no abandona el momento inicial de la pura descripción. Ana Pizarro (1985) insiste explícitamente en desligarse de dicha aglomeración (sea nacional o puramente espacial, lo mismo vale en este contexto) con el objeto de definir América Latina. Para colmo, Rama no alcanza a refinar su postulación y, tal como la presenta en 1965, acarrea al menos dos lastres: uno es la tendencia a identificar las comarcas con áreas geográficas muy puntuales, incluso físicamente aislables (al Caribe debe agregarse en este punto la "comarca andina»); otro es la liviandad con que vuelve al facilismo de lo nacional para intentar resumir la variedad de México o para eludir la extrańeza que provoca ese otro invitado incómodo en Latinoamérica: el Brasil.

En otro aspecto, lo comarcano vuelve a trazar una división, si bien motivada por el recorte metodológico, allí donde ciertos fenómenos estéticos ya habían resuelto el problema teórico con una eficacia práctica indudable: son los casos del Barroco y el Modernismo hispanoamericanos, que constituyen ejemplos ya no transnacionales sino supranacionales. Lo transnacional sigue ligado al Estado-nación, en tanto lo supranacional trasciende límites y soberanías y se afinca en una comunidad lingüística más propicia a un ejercicio estético consensuado que a una voluntad de comunicación efectiva. La ventaja de lo supranacional no es solamente la anulación del fetiche estatalista sino asimismo el desafío a los criterios nacionales que siguen operando en las academias centrales y que muchas veces han sido copiados en las instituciones de enseñanza latinoamericanas que continúan delimitando los objetos de estudio con la incómoda etiqueta de literaturas nacionales.

La supranacionalidad es una expectativa idealista que de ninguna manera abriga la pretensión de arrasar la heterogeneidad, sino que se ofrece como frente común de resistencia ante la pretensión metropolitana atropelladora de definir qué es y cómo debe entenderse América Latina. Enrolado en el entusiasmo utópico pero proclive a concreciones urgentes, Antonio Cornejo Polar representa una iniciativa teórica y crítica que repone el mito de Anteo, cuya fuerza radica en el contacto con la tierra propia. Así, propuso un «latinoamericanismo vernáculo» y lanzó la Revista de Crítica Literaria Latinoamericana en 1975 como vehículo de difusión y coordinación de publicaciones amparadas por la comunidad imaginada del Sur Global. Sobre esa fundación, instalada en «las entrańas del monstruo» — devenidas zona franca de circulación de ideas- se encaramarían en las décadas siguientes, junto a las variantes nominales del colonialismo ya consignadas, los diagnósticos proliferantes de la "colonialidad del poder» elaborados por Aníbal Quijano para revitalizar unas ciencias sociales cuyas generalidades no alcanzaban a dar cuenta de aspectos puntuales del continente (Quijano, 2000).

En la serie a la cual tributan todos los nombres y los propósitos revisados hasta ahora quisiera inscribir esta iniciativa, informada por tal variedad que conforma un créole teórico, cuya virtud sobresaliente es la de reemplazar los tecnicismos 
académicos por el rescate de prácticas culturales que han sido aisladas o soslayadas. Es así como escapa a la colonialidad de la teoría emanada e impuesta desde las academias metropolitanas. La postulación en que me empeño convoca al comparatismo como modo de afirmar y consolidar las diferencias para poder darles cohabitación a partir del reconocimiento y no de la simplificación; por eso, en vez de la prédica universalizante de la Weltliteratur opta por inscribirse en la órbita del cimarronaje. Los latinoamericanos que se amotinan en la mezcla y hacen del mestizaje una divisa — relegando al mulataje que delata una circunscripción mayor frente a la amplitud del otro cruce- abandonan la dependencia cultural como los esclavos fugitivos escapan a los rigores del amo y a las abstracciones brutales del sistema de sujeción. En esa intersección gozosa, la del créole y el cimarronaje, delineo el comparatismo latinoamericano, intraamericano para más precisión, de ansias supranacionales y defensa comarcana, plagado de tantas heterogeneidades que solamente puede sostenerse sobre un mestizaje abusivo y un mulataje desfachatado.

\section{Voluntad y alcances}

Lo primero que quisiera especificar es el alcance de semejante comparatismo, que en parte fue perfilado en esa reunión de 1983 en la Universidad de Campinas en la que se trataron los criterios para una historia de la literatura latinoamericana ( $\mathrm{Pi}-$ zarro, 1985). El Informe Bernheimer de 1995, presentado ante la ya vapuleada American Comparative Literature Association (ACLA) por los recuentos previos de Harry Levin y Green y por el reproche vehemente de René Wellek en 1958, expande las posibilidades de la disciplina incluyendo en ella los discursos no literarios (históricos, sociológicos, antropológicos) y los que prescinden de soporte verbal (las artes plásticas). Según tal criterio, el ensayo pasa a ser apenas una forma discursiva sometida al vínculo con las formas tradicionalmente literarias - los géneros convencionales y presuntamente estables- y no el modo de enunciación más ajustado a la formulación de una teoría, como estoy proponiendo ahora.

El comparatismo clásico dispuso un modelo plagado de europeísmo y centralismo, que hizo del concepto de influencia una de sus insignias, prolijamente desestabilizado por Rafael Gutiérrez Girardot en su brillante estudio sobre el modernismo (1983). En las aberraciones con que la literatura comparada se expandió luego de que René Wellek decretara su crisis en 1958, se impuso la convicción de que solamente se podía practicar comparatismo en lenguas diferentes. Así se procuraba - en la estela fundacional de la Weltliteratur — combatir las veleidades de los estados nacionales, aunque a costa de ignorar deliberadamente que diversos estados nacionales pueden compartir una lengua. A lo sumo se admitía un comparatismo absolutamente opresivo según el cual las colonias (antiguas o presentes) de una nación imperialista debían integrar sus producciones literarias al rigorismo centralista, en función de ofrecer un contraste periférico que contribuyera a certificar la superioridad de la metrópoli. Los juicios de valor eran condición inicial para el ejercicio del método y su variante más concurrida era la que operaba en función de 
las dudosas e inevitablemente subjetivas distinciones de superioridad e inferioridad, aplicadas según un cartabón maniático.

Esa variante de la colonialidad no forma parte de los desvelos académicos que se especializan en lo poscolonial. A su vez, semejante comparatismo alucinado por magnitudes arbitrarias — que ratifica la división entre centro y periferia, entre metrópoli y colonia, en lugar de someterla a un escrutinio que le depare el escarnio correlativo a su suficiencia - representa en el caso específico del desintegrado imperio luso un impedimento adicional a los que ya existen en torno a la participación de Brasil en el orden latinoamericano. En parte por la comodidad de Hispanoamérica para reconocerse como comunidad lingüística —obliterando, en la insuficiencia de un nombre que fue eficaz en el siglo XIX, las lenguas indígenas originarias y las africanas transplantadas, además de las múltiples creolizaciones que transitan desde el papiamento holando-antillano de raíces esclavistas hasta el cocoliche porteño de causas inmigratorias-, en parte por el confort que el mismo Brasil desarrolla al mantener modos de producción y circulación ajenos a las editoriales y las revistas latinoamericanas para liberarse, en consecuencia, de la tiranía de sus mecanismos (pero apartándose, por lo mismo, de las ventajas de sus instrumentos). No se trata de una conducta uniforme y es cierto que existen ejemplos intelectuales de aproximación —Darcy Ribeiro y Antonio Candido son los más relevantes en la segunda mitad del siglo XX, y es sintomático el hecho de que hayan sido los interlocutores privilegiados por Rama en ese orden- pero parece ser una dinámica de la academia brasileña, abismada por igual en el encierro de la literatura vernácula y en el comparatismo conservador que exige el dominio de al menos una lengua central.

El comparatismo que propongo abjura de tales limitaciones; contra la uniformidad imperialista y el nacionalismo estrecho se afianza en la unidad soberana y aspira a comparar para unificar. Con tal propósito se desliza entre lo comarcano y lo supranacional. Desde la primera dimensión incorpora espacios habitualmente resistidos por una mirada que, en sus ansias sistematizadoras, suprime lo que no ingresa con facilidad dentro de los criterios generales. Por eso incorpora a Brasil y descree de la trampa lingüística agitada como excusa para el apartamiento, y con las mismas ínfulas convoca al Caribe francés y admite la limitación del término Latinoamérica para dar cuenta de otros fenómenos culturales que participan con idéntico derecho de la unidad teórica, como el Caribe inglés y el holandés, cuyos territorios han devenido países independientes que no pueden permanecer aislados en función de una colonización diversa; al contrario, la experiencia misma de la colonización, con las marcas históricas y culturales que imprime, debería funcionar como acicate para sumarlos a la expectativa comparatista. Si eso ocurre en el orden comarcano, en el supranacional el proyecto apunta a contrastar los productos culturales desterrando la amenaza de la jerarquía y apaciguando en un ejercicio metódico y esperanzado tanto la superficialidad de un parangón que se remite a aplicar un modelo sin una hipótesis que justifique el ejercicio como el entusiasmo descabellado que, en pos de la utopía unificadora, anule las diferencias y abra un resquicio frente a una colonización que puede ser más limitada — restringida a una única dimensión - pero no por ello menos nociva.

En lugar del antiguo artilugio de convertir la cultura latinoamericana en la articulación forzada de un conjunto de culturas nacionales, y apenas episódicamente regionales, la supranacionalidad del planteo la aborda como un hipertexto, sin 
renunciar a la individualidad y asegurando un tratamiento diferencial, mediante sucesivas ventanas a las que el comparatismo les ofrece una posibilidad de sincronía que otros métodos impiden, o al menos limitan. Como en una computadora, la capacidad para mantener varias ventanas abiertas simultáneamente, para pasar de una pantalla a otra, para articular la lectura entre ellas, depende no solamente de la maleabilidad del lector sino también de la solvencia del equipo. Es en tal sentido que quisiera refinar la analogía exponiendo las condiciones que estimo ideales — toda teoría es una manifestación de deseos— para su desarrollo.

\section{Recaudos}

Retomar el comparatismo puede ser blanco de objeciones. Una, que creo haber desestimado precisamente por la heterodoxia del método a la que apelo, es la de que se trata de un ejercicio que se enorgullece de deparar exclusiones al instalar como exigencias el manejo de literaturas y lenguas centrales. Para contrarrestar su incidencia, particularmente notoria en América Latina a partir del crecimiento que registró durante la posguerra en las universidades norteamericanas, se ofrecieron como alternativa los Estudios Culturales, en cuya órbita resultaba admisible todo lo que el comparatismo erradicaba: culturas minoritarias, culturales populares sin reconocimiento académico, contemporaneidades estrictas y fenómenos de reivindicación como el feminismo, del cual se desprendieron los estudios de género. La situación histórica puntual y el modo de resolución del conflicto - que consta en el referido Informe Bernheimer- alimentó el prejuicio sobre sus principios. A su vez, quienes se encastillaban en los privilegios que el comparatismo reclamaba, se empeñaron en acorralar otras perspectivas, acusándolas de falta de rigor.

En América Latina el conflicto resultó potenciado, en parte porque la condición dependiente multiplica la resonancia de lo central, en parte porque las reacciones suelen quedar enmarcadas en el maniqueísmo que exige la adhesión acrítica o el rechazo absoluto, y raramente opta por el juicio equilibrado o apenas el desinterés frente a algo que no corresponde a los parámetros propios y que, si puede prestar cierto servicio local, es a costa de adaptaciones excesivas o deformaciones inevitables. En lugar de una reticencia saludable o una abstención sensata, la dependencia se expande a través de la influencia, que presupone una relación unidireccional y la aceptación pasiva por parte de quien la recibe. En el comparatismo latinoamericano la influencia no acude a apuntalar el sosiego del investigador que encuentra en ella un sostén para su trabajo, sino que se presenta como una amenaza que urge señalar. De allí que las categorías pretendidamente universales que emplean las teorías reclamen un ajuste permanente, si no una suspensión, cuando intervienen en el orden latinoamericano, donde se verifica que la universalidad es una construcción humanista tan endeble como la globalidad en tanto elaboración poscolonial.

Contra un trabajo comparatista que se obstina en perseguir influencias y que, en combinación con la filología, hace del rastreo de fuentes una actividad más 
intensa que la indagación del modo en que tales fuentes se manifiestan en otras producciones estéticas, el comparatismo programático que procuro delinear se empecina en restituir relaciones donde todavía no son visibles. La reposición de vínculos funciona en un plano hipotético, en tanto vocación promisoria, como la resumió Manuel Asensi Pérez:

hay que crear una relación allí donde no la hay, allí donde la intertextualidad, el injerto o el palimpsesto no ha sido posible por un acto de violencia y represión. Por eso, la literatura comparada o poética relacional tiene como uno de sus objetivos primordiales el estudio de las razones por las cuales no hay relación. (2010: 90)

Quisiera ańadir otro elemento adicional a este comparatismo que no se pliega a la hipóstasis del dominio de lenguas, pero tampoco prescinde por completo de tal destreza, y que reconoce en la traducción la posibilidad de ampliar el acceso a una cultura necesariamente plural (Bosi, 2005: 277-278). Existen obras y autores que, sin manifestarse en una lengua latinoamericana, forman parte indisoluble de América Latina e incluso contribuyen a su definición. Los textos de Alexander von Humboldt que dan cuenta de sus viajes por América —e incluyen la subida al Chimborazo, como antecedente independentista mítico, o la topografía de la isla de Cuba- y los de Graham Greene que recorren los países en tramas novelísticas capaces de articular la insurrección cristera en el México de El poder y la gloria, los estertores finales del gobierno de Fulgencio Batista en la Cuba trasnochada de Nuestro hombre en La Habana y la vinculación entre Argentina y Paraguay mediante los focos guerrilleros que ocupan las páginas de El cónsul honorario, integran la cultura latinoamericana. La procedencia germánica de Humboldt y la británica de Graham Greene no pueden ser argumentos en contra de su inclusión sino perversas distracciones dentro de un programa integrador.

Que Humboldt escribiera en francés y Graham Greene en inglés son datos menores a los fines no ya de mi empecinamiento sino del mismo propósito de ellos. La confirmación de semejante voluntad consta en la curiosidad lingüística que informa que la versión alemana de las cartas y textos científicos de Humboldt es ya una traducción - dato que invierte el empeño menos decimonónico que iluminista de clasificar mediante latinismos que campea en su compañero Aimé Bonpland cuando encara la taxonomía de la flora americana, lo que fue lúcidamente ironizado por Ibsen Martínez en su obra Humboldt y Bonpland taxidermistas (1991) — y en el desenfado con que el Servicio Secreto británico que interviene en el Caribe en Nuestro hombre en La Habana homologa el francés al español, en tanto ambas son lenguas latinas. A fin de seguir acumulando razones de inscripción de cada uno en la cultura latinoamericana, agrego que Humboldt se convirtió en personaje de La fragata de las máscaras, la novela de Tomás de Mattos que continúa Benito Cereno de Herman Melville y ubica en la Lima en que se encuentran Humboldt y Bonpland el juicio al capitán melvilliano, en tanto Graham Greene mantuvo una firme amistad con el general panameño Omar Torrijos.

Como se advierte, el comparatismo intraamericano, comarcano y supranacional reviste múltiples justificaciones para erigirse en método plausible a fin de abordar un objeto versátil y plural, que esquiva las definiciones esencialistas y las caracterizaciones rígidas y renuncia a teorías y nomenclaturas de origen metropolitano, no porque las tilde de extranjeras - lo que resulta irrisorio al cabo del arco abarcativo 
recién esbozado - sino porque acarrean vocación imperial o porque apuntan a una conciliación que solamente es posible mediante la disolución o la supresión de las diferencias. Para admitir al comparatismo como método urge quitarle el barniz colonialista y recuperarlo en tanto estrategia de aproximación.

A fin de no mantener la propuesta en un orden de abstracción excesivo, una vez establecidas las posibilidades metodológicas y los principios operativos me detengo en el caso que estimo como la mayor urgencia para promover un latinoamericanismo efectivo: la integración de Brasil, superando el estrecho espacio comarcano de la triple frontera del litoral argentino, el norte uruguayo y el sur gaúcho que desarrolla una cultura donde el portuñol guaranizado es lengua de cruce y síntesis.

\section{Brasil}

Las analogías más habituales entre Brasil y el resto de América Latina abusaron del Modernismo brasileño, que arrastra una nomenclatura superpuesta con la del área hispanoamericana, ya que no es un equivalente de lo que aquí se designa modernismo, sino de las vanguardias. Dado que las vanguardias impactan en todo el continente de manera similar - conmoviendo las expresiones arcaicas y clásicas, reclamando la manifestación de síntomas de la modernización acelerada - y hacia la misma época, se trata de un fenómeno que favorece el ejercicio comparativo porque abunda en similitudes. Sin embargo, si hay algo que el comparatismo que fomento defiende especialmente es la necesidad de desarrollarse como práctica contrastiva y diferencial (Pizarro, 1985: passim), que en otro lugar llamé provocativamente comparatismo al estilo Tom Castro (Croce, 2013), identificado con el personaje borgeano cuyo mentor, consciente de que cualquier semejanza tiende a resaltar los puntos de no coincidencia, prefiere operar en función de diversidades.

Para no sobreabundar en un campo demasiado transitado, desde la literatura y desde las artes, me detengo en una figura que la cronología de la historia literaria ubica exactamente antes del Modernismo brasileńo: Afonso Henriques de Lima Barreto, a quien conviene caracterizar inicialmente por su situación dentro de lo que con preclara decisión Antonio Candido llamó «sistema literario». Lima Barreto se ubica así en un lugar ajeno a la canonización de su relativo contemporáneo Machado de Assis, tanto por la condición de mulato pobre como por su preferencia por el realismo francés frente a la ironía inglesa machadiana; asimismo en su función de inaugurador de la novela brasileña moderna, renovador de la prosa que sienta las bases para la desenvoltura de lenguaje que implementará el Modernismo y manipulador desenfadado de los clásicos, por lo que logra reunir en Triste fim de Policarpo Quaresma (1915) el ilusionismo quijotesco del personaje con la crítica balzaciana a la sociedad de la Primera República y con la demolición flaubertiana de toda empresa que encara el personaje, lo que convierte a Quaresma en una variante unitaria de Bouvard y Pécuchet.

En el marco de la literatura comarcana del Cono Sur, Lima Barreto enlaza con Elías Castelnuovo en su preferencia por los personajes marginales y monstruosos, 
y con Roberto Arlt en su mirada corrosiva sobre la ciudad que da pie a aguafuertes irreductibles ante la modernización pertinaz del paisaje carioca (encarada por la piqueta inclemente del prefecto Pereira Passos). En el orden cultural, sus adhesiones son más diversas: si se pliega, como el escultor mulato mineiro Antônio Francisco Lisboa (el Aleijadinho), a perfilar retratos destemplados de contemporáneos que le provocan rechazo o desdén, el énfasis en la comicidad funesta es un rasgo chaplinesco que subraya la renuncia a la ironía calculada de Machado para incurrir en una sátira descarnada que es el modo más severo de pronunciamiento crítico y ético.

Triste fim de Policarpo Quaresma constituye la paradójica enciclopedia de la historia cultural de Brasil, donde los personajes a los que el discurso histórico había connotado con rasgos sobresalientes reaparecen en términos puramente denotativos (de Certeau, 1993), acentuando el contraste con la construcción oficial. Quaresma se postula, además, con su continencia rutinaria y su acérrima defensa nacionalista, a modo de contracara esquemática pero no por eso menos violenta de una cultura de fachada identificada por el carnaval, desbordante y excesiva, proclive a intervenciones de toda procedencia. En el carnaval ostentoso, Lima Barreto no reconoce el rasgo brasileño que ha establecido la imagen de exportación del país, sino una improvisación disfrazada de pasión. Los juicios lingüísticos que campean en el texto, en tanto, no apuntan a la entronización del portugués sino a la recuperación del tupí (justamente algo que el Modernismo convertirá en manifestación hiperbólica y provocadora con Tupi or not tupi, that is the question y lo que el Integralismo reaccionario enarbolará desde el saludo Anauê complementado por la calistenia fascista), que perturba al personaje hasta el punto de acarrearle un conflicto burocrático que da pie a la ridiculización de los sabios. Estos, ignorantes de las lenguas indígenas, procuran establecer analogías remotas y sospechas inauditas, como la que decide que la doble $\mathrm{Y}$ en un texto es una señal inequívoca del griego.

Si Lima Barreto resulta una figura de relieve para sostener un comparatismo comarcano y a la vez supranacional es también porque presenta al nacionalismo (en este caso, el fomentado por la República Velha brasileña) como patología. Los proyectos nacionales fracasan sucesivamente en las manos voluntariosas pero inexpertas de Policarpo Quaresma, sea el de la chacra asolada por las temibles saúvas destructoras o el de la reposición del tupí como lengua de la patria, ya que patria y nación quedan igualadas y eso convierte a la Guerra del Paraguay en una dudosa empresa patriótica en lugar del oprobio imperial de la alianza con Argentina y Uruguay para aniquilar a la entonces potencia americana (como se advierte, las alianzas comarcanas puntuales de América han sido más exitosas en su faz arrasadora que en la esperanzada, como certifica en la proximidad histórica el Plan Cóndor en tanto falange de exterminio).

También es Lima Barreto quien permite retornar al punto de partida de este artículo, ya que la voluntad de diagnosticar los males locales, aunque permaneciendo enfrascada en ellos ante la desventura de quienes procuran corregirlos, es una de las señales del dependentismo. La actitud momentáneamente ufanista del personaje quijotesco no hace más que amplificar el efecto de su desazón. La distancia que intento marcar aquí responde a la actitud que defiendo respecto de esa comprobación desoladora: no ya el resentimiento como motor de la historia - y esto certifica también mi apartamiento del Marx a quien convoqué como modelo discursivo-, en vistas de que la condición dependiente no es modificable al menos 
en lo inmediato, sino la expectativa en una resolución cultural de un conflicto mucho más abarcativo. Eso quiere ser el comparatismo que se desplaza entre lo comarcano y lo supranacional: un ideologema de la teoría latinoamericana frente a las evidentes limitaciones de los modelos disponibles.

Este comparatismo intraamericano acude al recorte comarcano para postular desde allí una supranacionalidad que no se resuelve en pura sumatoria sectorial sino que surge como vehemencia entusiasta amparada en la libertad enunciativa con que discurre el ensayo. En tal elección expresiva se perfila su afán de ficción teórica, confirmada por el recurso a textos específicos menos como modo de aplicación de su vocación metódica que como complemento de elaboración de sus alcances. La revisión de la «comarca brasileña» que tiene el inconveniente de ser una equívoca comarca nacional (lo que lleva a naufragar al concepto en el momento mismo de su enunciación, excepto que se lo apuntale con precisiones y recaudos) flexiona tanto hacia la confirmación de idoneidad del método que la comprende como hacia la necesidad de incorporarlo en un abordaje integrador. Desde ya, se trata de un proyecto perfectible y de un método que reclama refinar sus herramientas y habilitar nociones teóricas que lo complementen y lo sustenten, pero es un impulso independiente en un campo plagado de nomenclaturas y conceptos pensados fuera de Latinoamérica y más propicios a disputas de poder que a reclamos concretos de los objetos en función de los cuales deberían justificarse.

\section{Referencias bibliográficas}

Asensi Pérez, M. (2010). «La oveja perdida y la emancipación de la literatura comparada» en Morales Mena, J. (comp.). La trama teórica. Escritos de teoría literaria y literatura comparada. Lima: Editorial San Marcos, pp. 79-95.

Bernheimer, Ch. (ed.) (1995). Comparative Literature in the Age of Multiculturalism. Baltimore and London: The John Hopkins University Press. Bosı, A. (2005). "Culturas brasileñas» en Bosı, A. Cultura brasileña. Una dialéctica de la colonización. Salamanca: Universidad de Salamanca, pp. 277-306.

Candido, A. (2008). Formação da literatura brasileira. Momentos decisivos 1750-1870. Rio de Janeiro: Ouro sobre Azul.

Cornejo Polar, A. (2003). Escribir en el aire. Lima: Centro de Estudios Literarios «Antonio Cornejo Polar».

Croce, M. (2013). "Comparatismo: el método de la supranacionalidad». En Croce, M. (ed.) Latinoamericanismo. Canon, crítica y géneros discursivos. Buenos Aires, Corregidor, pp. 13-18.

De Certeau, M. (1993). La escritura de la historia. México: Universidad Iberoamericana.

FAnON, F. (2008). Los condenados de la tierra. México: Fondo de Cultura Económica. 
Gutiérrez Girardot, R. (1985). «El problema de una periodización de la historia literaria latinoamericana» en Pizarro, A. (coord.) La literatura latinoamericana como proceso. Buenos Aires: Centro Editor de América Latina, pp. 119-131.

(1987). Modernismo. Supuestos históricos y culturales. México: Fondo de Cultura Económica.

Henríquez Ureña, P. (2000). «La utopía de América» en Henríquez Ureña, P. Ensayos. Edición de José María Abellán y Ana María Barrenechea. Buenos Aires: Archivos, pp. 266-272.

Pizarro, A. (coord.) (1985). La literatura latinoamericana como proceso. Buenos Aires: Centro Editor de América Latina.

Quijano, A. (2000). «Colonialidad del poder, eurocentrismo y América Latina» en LANDER, E.(ed.) La colonialidad del saber: eurocentrismo y ciencias sociales. Perspectivas Latinoamericanas. Buenos Aires: CLACSO, pp. 201-246.

Rama, A. (1979). Aportación original de una comarca del Tercer Mundo: Latinoamérica. Cuadernos de Cultura Latinoamericana, (73). México: UNAM.

(2008). «Diez problemas para el novelista latinoamericano» en Rama, A. La novela en América Latina. Panoramas 1920-1980. Santiago de Chile: Ediciones Universidad Alberto Hurtado, pp. 45-113

(2008). Transculturación narrativa en América Latina. Buenos Aires: El Andariego.

Schwarcz, L.M. (2017). Lima Barreto: triste visionário. São Paulo: Companhia das Letras.

Sorá, G. (2017). Editar desde la izquierda en América Latina. La agitada historia de Fondo de Cultura Económica y de Siglo XXI. Buenos Aires: Siglo XXI.

Wellek, R. (1963). "The Crisis of Comparative Literature (1958)» en Wellek, R. Concepts of Criticism. New Haven and London: Yale University Press.

\section{Croce, Marcela}

«Comparatismo cimarrón: un método supranacional». El hilo de la fábula. Revista anual del Centro de Estudios Comparados (19), 25-37.

Fecha de recepción: $01 \cdot 02 \cdot 19$

Fecha de aceptación: $15 \cdot 03 \cdot 19$ 